\title{
Effectiveness of Nd:YAG Laser on the elimination of debris and Smear Layer. A comparative study with two different irrigation solution: EDTA and QMix ${ }^{\circledR}$ in addition to $\mathrm{NaOCl}$
}

\author{
Paloma Montero-Miralles, Roberto Estévez-Luaña, César DeGregorio-González, Oliver Valencia-dePablo, Da- \\ vid E. Jaramillo, Rafael Cisneros-Cabello
}

\author{
${ }^{1}$ Universidad de Sevilla. School of Dentistry. Sevilla \\ Correspondence: \\ Universidad de Sevilla \\ School of Dentistry \\ Avicena S/N. 41009 Sevilla \\ montero_paloma@hotmail.com
}

Received: $10 / 09 / 2017$

Accepted: 06/12/2017

\begin{abstract}
Montero-Miralles P, Estévez-Luaña R, DeGregorio-González C, Valencia-dePablo O, Jaramillo DE, Cisneros-Cabello R. Effectiveness of Nd:YAG Laser on the elimination of debris and Smear Layer. A comparative study with two different irrigation solution: EDTA and QMix ${ }^{\circledR}$ in addition to NaOCl. J Clin Exp Dent. 2018;10(1):e70-4. http://www.medicinaoral.com/odo/volumenes/v10i1/jcedv10i1p70.pdf
\end{abstract}

\begin{abstract}
Background: The aim of this study was to evaluate the effectiveness in dentin debris and smear layer removal from root canal walls using EDTA and QMix ${ }^{\circledR}$ alone and also activated with Nd:YAG laser.

Material and Methods: 50 single-rooted teeth were instrumented and divided in 5 groups according to irrigation protocol: 17\% EDTA, QMix ${ }^{\circledR}, \mathrm{Nd}: Y A G$ laser alone, and combination of 17\% EDTA - Nd:YAG laser and QMix ${ }^{\circledR}$ - Nd:YAG laser. Samples were evaluated using SEM. Statistical analysis was done using Chi-Square Fisher exact test and McNemar test.

Results: Dentinal debris analysis showed statistically significant differences when comparing 17\% EDTA vs Laser and Laser vs QMix ${ }^{\circledR}$ in combination with Laser at the apical third. The Smear Layer analysis also showed statistically significant differences at the apical third when comparing $17 \%$ EDTA vs Laser, QMix ${ }^{\circledR}$ vs QMix ${ }^{\circledR}$ in combination with Laser and Laser vs QMix ${ }^{\circledR}$ in combination with Laser.

Conclusions: 17\% EDTA was the most efficient irrigant showing the best results. Laser alone was not effective removing either dentinal debris or smear layer.
\end{abstract}

Key words: Laser, endodontics, Smear Layer.

\section{Introduction}

The smear layer is a microscopic layer formed after root canal instrumentation and located along the root canal walls. It blocks dentinal tubule orifices and creates an interface between filling material and root canal wall, affecting sealing ability of the root canal system. The width of this layer is between 1 to 2 microns (1) and it reduces penetration of irrigants and sealers into dentinal tubules $(2,3)$.
Some studies have shown that mechanical instrumentation and chemical action of $\mathrm{NaOCl}$ are not enough to remove the smear layer totally from the root canal wall $(4,5)$. Chelating agents are used for its removal. QMix ${ }^{\circledR}$ (Denstply-Maillefer, Tulsa, USA) has been recently launched, composed of an antimicrobial agent, Chlorhexidine, mixed with a chelating agent, EDTA, and a surfactant (6).

Laser technology has been developing for several years 
and has become more widely used in the medical and dental field. Its effectiveness will depend upon such factors as: energy level, duration of exposition, absorption in tissues, root canal geometry and the distance between the tip of the laser and the tissue being treated (7-9). The most studied laser in dental literature is the Neodymium:Yttrium-Aluminium-Garnet (Nd:YAG), with a wavelength of $1064 \mathrm{~nm}$ and possessing partial water absorption. In endodontics, its effect on the root canal wall produce removal of smear layer and pulp tissue remnants, root canal decontamination, organic tissue vaporization inside dentinal tubules and fusion and crystallization of the inorganic component of the dentin (melting). It also produces physical-chemical changes on hydroxyapatite crystals, which modifies dentin solubility, thus becoming less susceptible to acids action.

The objective of the present study was to evaluate the cleaning capability of QMix ${ }^{\circledR}, 17 \%$ EDTA in combination with sodium hypochlorite, plus the action of Nd:YAG laser alone and with the previous chelating solutions.

\section{Material and Methods}

This study was approved by the Ethical Committee of the European university of Madrid.

50 freshly extracted single-rooted human teeth were kept in $10 \%$ formalin until used. Inclusion criteria were: presence of only one root canal, complete apical closure and no previous root canal treatment done prior to its use.

The crowns of all teeth were cut off with the use of a diamond disk (Buehler, Düsseldorf, Germany) and tooth length standardized to $16 \mathrm{~mm}$. A glide path was performed with a \#20 hand K-Flexofile (Denstply-Maillefer, Tulsa, USA) and the cleaning and shaping of the root canal was completed using the Mtwo ${ }^{\circledR}$ rotary system (VDW, Munich, Germany) up to 40.04 to $15 \mathrm{~mm}$. Care was taken to keep root canal patency at all times.

During instrumentation, the root canal was irrigated in between files with $1 \mathrm{ml}$ of $4.2 \% \mathrm{NaOCl}$ using a $5 \mathrm{ml}$ Monoject irrigation syringe and a $27 \mathrm{~g}$ irrigation needle (Tyco HealthCare Group, Norwalk, CT, USA) that was kept $1 \mathrm{~mm}$ short of the working length. After this step, teeth were kept in saline solution until processed for SEM.

Samples were randomly divided using the software www.random.org into 5 groups of 10 teeth each. For the final irrigation cycle, all roots were sealed apically with modeling wax (Cera Reus, Reus, Spain) and a reservoir was created coronally.

Study groups:

Group 1: 1 minute of irrigation with $5 \mathrm{ml}$ of 17\% EDTA (Pulpdent, Oakland, MA, USA), followed by $5 \mathrm{ml}$ of $4.2 \% \mathrm{NaOCl}$ for 2 minutes and a final rinse with $2.5 \mathrm{ml}$ distilled water.

Group 2: 1 minute of irrigation with $5 \mathrm{ml}$ of $\mathrm{QMix}{ }^{\circledR}$
(Denstply-Maillefer, Tulsa, OK, USA) and a final rinse with $2.5 \mathrm{ml}$ distilled water.

Group 3: Nd:YAG laser (DEKA, Firenze, Italy), followed by described protocol by Gutknecht and Behrens: power set at $1.5 \mathrm{~W}, 15 \mathrm{~Hz}$ and $100 \mathrm{~mJ}$ of energy [10]. Wavelength of $1.064 \mathrm{~nm}$. A 320 microns optic fiber was used with an apical to coronal helicoidal motion. Working length was established at $15 \mathrm{~mm}$. A rubber stop was placed on the fiber optic tip at $14 \mathrm{~mm}$ to set this as a working field for the laser. The laser was activated on a 5 seconds cycle five times taking a rest for 20 seconds in between each cycle. $2.5 \mathrm{ml}$ of distilled water was used as a final rinse (Fig. 1).

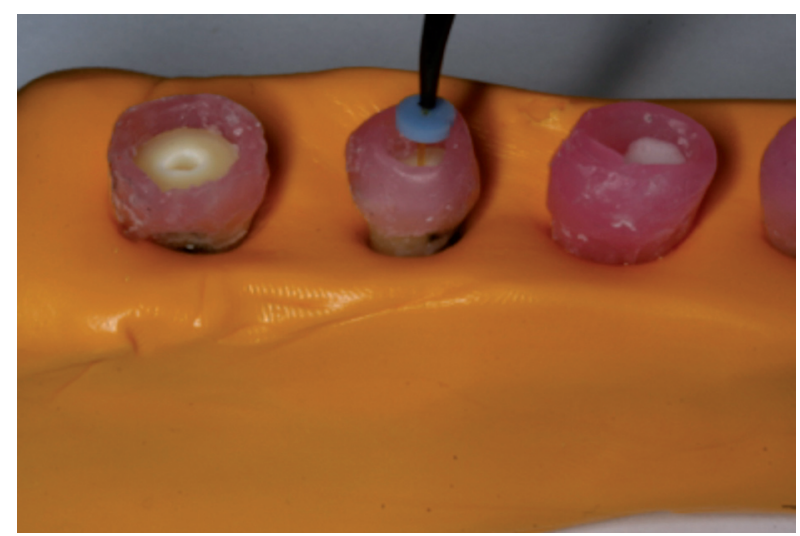

Fig. 1: Nd:YAG laser application.

Group 4: 1 minute of irrigation with $5 \mathrm{ml}$ of 17\% EDTA plus laser. The laser tip used as previously described; then, a rinse with $5 \mathrm{ml}$ of $4.2 \% \mathrm{NaOCl}$ for 2 minutes and a final rinse with $2.5 \mathrm{ml}$ of distilled water.

Group 5: 1 minute of irrigation with $5 \mathrm{ml}$ of $\mathrm{QMix}{ }^{\circledR}$ in combination with laser, used as previously described and a final rinse with $2.5 \mathrm{ml}$ of distilled water.

Roots were longitudinally split using a 20x0.25 mm fine diamond disk (Buehler, Düsseldorf, Deutschland) in a low speed motor (NSK, Japan), avoiding passing the disk through the root canal lumen to prevent the accumulation of sectioning debris. With the help of a fine chisel and with a very fine pounding, both halves of the root were obtained.

Roots were treated with a serial dilution of different concentrations of alcohol (30\% to $100 \%)$ for the dehydration process. Samples were mounted on a special stainless steel base and taken inside the sputtering machine to be coated with a fine layer of graphite (Blazer Union Med 010). Immediately after, the samples received a $25 \mathrm{~nm}$ layer of gold (Emitech K550X). A total of 60 samples were observed under SEM. A SEM (JEOL JSM-6400) microscope was used with a $20 \mathrm{kV}, 100 \mathrm{~mA}$. The working distance was set at $39 \mathrm{~mm}$. A specific area of the 
apical and middle third of the root canal was chosen to be the observation spots.

Pictures were randomly taken first at 20X magnification for the correct localization of the observation spot. Images were centered at the apical zone in order to observe the mark left behind by the apical calibration instrument. At $0.5 \mathrm{~mm}$ from this spot a $100 \mathrm{X}$ image was taken. Two images were obtained at 500X and 1000X magnification. Magnification was established at 100x again to reach out the middle third, and two images were taken at $5 \mathrm{~mm}$ from the working length, at 500X y 1000X. The same procedure was done at the middle area of the root canal. All images were analyzed by a previously calibrated expert viewer. A modified Hülsmann classification (11) was used to measure at the $500 \mathrm{X}$ level for the presence of dentinal debris and at $1000 \mathrm{X}$ for the presence of Smear Layer (Fig. 2).

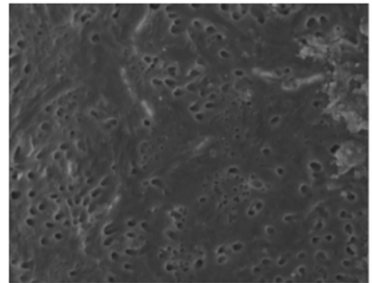

Score 3

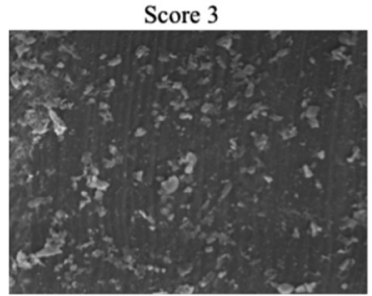

Score 1

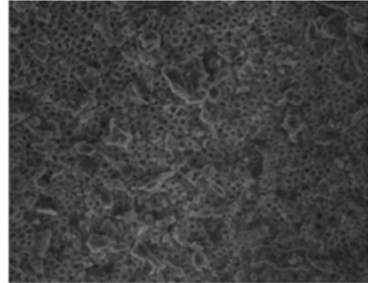

Score 2

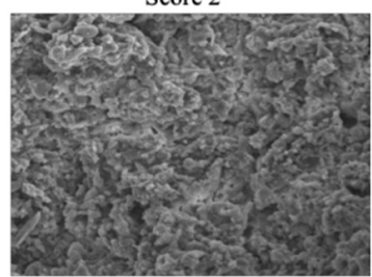

Score 0
Fig. 2: Hülsmann modified classification.

The scores values was assigned in this way:

Score 0: specimens showing a clean surface and most of the dentinal tubules open

Score 1: specimens showing most of the dentinal tubules open but remaining debris covering less than a $25 \%$ of the analyzed area

Score 2: specimens showing majority of dentinal tubules plugged with smear layer and remaining debris covering less than a $50 \%$ of the analyzed area

Score 3: specimens showing no dentinal tubules open and remaining debris covering less than a $75 \%$ of the analyzed area

Association between all groups and the degree of cleanliness, were evaluated using the chi-square and Fisher exact test for those cases where more than $25 \%$ of the samples were less than 5. For all the tests, a signification value of $5 \%$ will be accepted. The frequency distribution was evaluated within the variable results with 2 magnifications (500X and 1000X) using the McNemar test. Data was analyzed with the SPSS 15.0 software (SPSS Inc, Chicago, IL, USA).

\section{Results}

On dentin debris analysis, in the apical third, the best cleanliness was achieved by $17 \%$ EDTA in combination with laser and the results showed a statistically significant difference $(p=.015)$ when compared with the $17 \%$ EDTA group. Laser in combination with QMix ${ }^{\circledR}$ was found better $(p=.028)$ than QMix ${ }^{\circledR}$ alone. In the middle third, no statistically significant differences were found at any studied group.

The smear layer analysis, in the apical third, when comparing $17 \%$ EDTA in combination with laser $(p=.031)$ with $17 \%$ EDTA, the combination of EDTA and laser showed better results and a statistically significant difference. Also, a statistically significant difference was found when comparing QMix ${ }^{\circledR}$ and QMix ${ }^{\circledR}$ in combination with laser $(p=.029)$ where $\mathrm{QMix} \AA$ in combination with laser showed better results when comparing Laser in combination with $\mathrm{QMix}{ }^{\circledR}$ vs Laser, $(p=.03)$ a statistically significant difference was also found presenting QMix ${ }^{\circledR}$ in combination with laser better results. In the middle third, no statistically significant differences were found in any studied group, (Tables 1-3).

\section{Discussion}

The smear layer removal has been thoroughly investigated by many authors, during the last decades. The presence of this microscopic layer, could affect the adequate sealing of the root canal system. The removal of this inorganic matter, which contains some organic remnants as well, is particularly difficult in the apical third. The objective of the present study was to evaluate the cleaning ability of QMix ${ }^{\circledR}$ in combination with $\mathrm{Nd}$ :YAG laser compared to $17 \%$ EDTA, for the dentin debris and smear layer removal.

Root canals were prepared to 40.04 allowing the $320 \mathrm{mi}-$ crons Nd:YAG fiber laser tip to reach $1 \mathrm{~mm}$ short of the established working length and at the same time allow for a better flowability of the selected irrigant (12). By doing this, a size 44 diameter was made at the level where the laser tip was placed, which allowed enough space between the canal walls and this tip.

In order to simulate a clinical condition, we used modeling wax in the apex to keep the root canal system closed avoiding the extrusion of the irrigant used during the final rinse step. Dai et al. used an open system in their comparative study of smear layer removal using 17\% EDTA and QMix ${ }^{\circledR}$ (6). They concluded that it was not possible to completely remove the smear layer. Their results showed no difference. In the present study, 17\% EDTA and QMix ${ }^{\circledR}$ were not effective at apical and 
Table 1: Comparative debris and Smear Layer analysis in apical third (17\% EDTA and Laser).

\begin{tabular}{|c|c|c|c|c|c|}
\hline \multirow{3}{*}{$\begin{array}{c}\text { Apical } \\
\text { x500 }\end{array}$} & \multicolumn{2}{|c|}{ GROUP 1 (EDTA 17\%) } & \multicolumn{2}{|c|}{ GROUP 3 (Laser) } & \\
\cline { 2 - 6 } & 0 & $0 \%$ & 0 & $0 \%$ & \\
\cline { 2 - 6 } & 1 & $25 \%$ & 1 & $0 \%$ & \\
\cline { 2 - 6 } & 2 & $66,7 \%$ & 2 & $50 \%$ & \\
\hline \multirow{3}{*}{\begin{tabular}{c} 
Apical \\
\cline { 2 - 6 }
\end{tabular}} & 3 & $8,3 \%$ & 3 & $50 \%$ & $p=0.015$ \\
\cline { 2 - 6 } & 0 & $0 \%$ & 0 & $0 \%$ & \\
\cline { 2 - 6 } & 1 & $25 \%$ & 1 & $33,3 \%$ & $p=0.031$ \\
\hline
\end{tabular}

Table 2: Comparative debris and Smear Layer analysis in apical third (Laser and QMix ${ }^{\circledR}+$ Laser). $^{2}$

\begin{tabular}{|c|c|c|c|c|c|}
\hline & \multicolumn{2}{|c|}{ GROUP 1 (Laser) } & \multicolumn{2}{|c|}{ GROUP 3 (QMix ${ }^{\circledR}+$ Laser) } & \\
\hline \multirow{4}{*}{$\begin{array}{c}\text { Apical } \\
\text { x500 }\end{array}$} & 0 & $0 \%$ & 0 & $16,7 \%$ & \\
\hline & 1 & $0 \%$ & 1 & $25 \%$ & \\
\hline & 2 & $50 \%$ & 2 & $16,7 \%$ & \\
\hline & 3 & $50 \%$ & 3 & $41,7 \%$ & $p=0.028$ \\
\hline \multirow{4}{*}{$\begin{array}{l}\text { Apical } \\
\text { x1000 }\end{array}$} & 0 & $0 \%$ & 0 & $16,7 \%$ & \\
\hline & 1 & $0 \%$ & 1 & $33,3 \%$ & \\
\hline & 2 & $33,3 \%$ & 2 & $0 \%$ & \\
\hline & 3 & $66,7 \%$ & 3 & $50 \%$ & $p=0.003$ \\
\hline
\end{tabular}

Table 3: Comparative Smear Layer analysis in apical third $\left(\mathrm{QMix}^{\circledR}\right.$ and $\mathrm{QMix}^{\circledR}+$ Laser).

\begin{tabular}{|c|c|c|c|c|c|}
\hline & \multicolumn{2}{|c|}{ GROUP $2\left(\right.$ QMix $\left.^{\circledR}\right)$} & \multicolumn{2}{|c|}{ 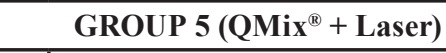 } & \\
\hline \multirow[t]{4}{*}{ Apical x1000 } & 0 & $0 \%$ & 0 & $16,7 \%$ & \\
\hline & 1 & $16,7 \%$ & 1 & $33,3 \%$ & \\
\hline & 2 & $33,3 \%$ & 2 & $0 \%$ & \\
\hline & 3 & $50 \%$ & 3 & $50 \%$ & $p=0.029$ \\
\hline
\end{tabular}

middle thirds. 17\% EDTA was superior to QMix ${ }^{\circledR}$ at all levels. There was a statistically significant difference in dentin debris removal at middle third. At this level, QMix ${ }^{\circledR}$ was better than $17 \%$ EDTA where dentinal tubules were clean $8.3 \%$ of the time, with no statistically significant difference.

Time and concentration for the application of chelating agents is an important factor (13). Dai et al. applied QMix ${ }^{\circledR}$ for 2 minutes while Stojicic et al., used it for 5 minutes (14). In our study, irrigation timing was standardized at 1 minute (15-18). By doing this, it was possible to obtain better results with QMix ${ }^{\circledR}$ vs $17 \%$ EDTA for the smear layer removal, without a statistically significant difference. More studies are needed to standardize the correct application timing for QMix.
For the smear layer removal, the recommended volume for $17 \%$ EDTA is in between 3 to $20 \mathrm{ml}$ per root canal $(11,17)$. Mello et al. showed that a final rinse with $5 \mathrm{ml}$ of $17 \%$ EDTA was as effective as $10-15 \mathrm{ml}$ of EDTA for smear layer removal (19). In our study, $5 \mathrm{ml}$ of $17 \%$ EDTA was used in accordance with Mello's study. In this study the specimens under treatment with laser, showed a minimal amount of open dentinal tubules. The parameters used were $1.5 \mathrm{w}$ of power, a frequency of $15 \mathrm{~Hz}$ and $100 \mathrm{~mJ}$ of energy (10). $100 \%$ of QMix ${ }^{\circledR}$ in combination with laser samples, presented a score of 2-3. QMix ${ }^{\circledR}$ in combination with laser samples and laser samples showed the same results at the middle portion of the root canal. Our results are in accordance with those from Hasheminia et al., Zhang et al., Barbakow et 
$a l$. , and Kivanc et al. Their results showed that Nd:YAG Laser is not as effective as EDTA for the smear layer removal (20-23).

The aim of our study was to show not only if the laser was effective in the removal of the smear layer, but also, if adding a chelating agent could improve its efficacy. When the apical third was studied, the group treated with QMix ${ }^{\circledR}$ in combination with laser, showed a better cleaning ability than using $\mathrm{QMix}{ }^{\circledR}$ alone. When the middle third was studied, dentin debris removal showed similar results in both groups, and the smear layer removal was better in the group irrigated with QMix ${ }^{\circledR}$. This could be explained because QMix ${ }^{\circledR}$ was used only for one minute and it might need more contact time to achieve better results as proposed by Stojicic et al. (14).

In all groups where the laser was used, a better smear layer removal was shown. No groups treated with EDTA obtained a value of 0 (complete clean surface), but there was always a superior cleanliness at the apical third (on both smear layer and dentin debris removal) although the difference was not definitive in the middle third.

Moura-Netto et al. (24) found in their study that Nd:YAG laser fuses and solidifies the dentinal surface with a partial removal of dentinal debris. In agreement with this study and based on the results obtained in the present study, we can conclude that we cannot compare the use of laser with the use of chelating agents, because these solutions possess the ability to dissolve smear layer, while lasers produce melting, vaporization and crystallization of this matter.

\section{References}

1. Mader CL, Baumgartner JC, Peters DD. Scanning electron microscopic investigation of the smeared layer on root canal walls. J Endod 1984;10:477-483.

2. Goldberg DB, Abramovich A. Analysis of the effects of EDTAC on the dentinal walls of the root canal. J Endod 1977;3:101-105.

3. Baumgartner JC, Mader CL. A scanning electron microscopic evaluation of four root canal irrigating regimens. J Endod 1987;13:147157.

4. Moodnik RM, Dorn SO, Feldman MJ, Levey M, Borden BG. Efficacy of biomechanical instrumentation: a scanning electron microscopic study. J Endod 1976;2:261-266.

5. Sulewski JG. Historical survey of laser dentistry. Dent Clin North Am 2000;44:717-752.

6. Dai L, Khechen K, Khan S, Gillen B, Loushine BA, Wimmer BS, Gutmann JL, Pashley D, Tay FR. The effect of QMix, an experimental antibacterial root canal irrigant, on removal of canal wall smear layer and debris. J Endod 2011;37:80-84.

7. Dederich DN, Zakariasen KL, Tulip J. Scanning electron microscopic analysis of canal wall dentin following neodymium-yttriumaluminum-garnet laser irradiation. J Endod 1984;10:428-431.

8. Tewfik HM, Pashley DH, Horner JA, Sharawy MM. Structural and functional changes in root dentin following exposure to KTP/532 laser. J Endod 1993;19:492-497.

9. Moshonov J, Sion A, Kasirer J, Rotstein I, Stabholz A. Efficacy of argon laser irradiation in removing intracanal debris. Oral Surg Oral Med Oral Pathol Oral Radiol Endod 1995;79:221-225.

10. Gutknecht N, Behrens V. Instrumentation of root canal walls with Nd:YAG laser. ZWR 1991;100:748-755.

11. Hülsmann M, Rümmelin C, Schäfers F. Root canal cleanliness after preparation with differend endodontic handpieces and hand instruments. A comparative SEM. J Endod 1997;23:301-306.

12. Usman N, Baumgartner JC, Marshall JG. Influence of instrument size on root canal debridement. J Endod 2004;30:110 -112.

13. Qian W, Shen Y, Haasapalo M. Quantitative analysis of the effect of irrigant solution sequences on dentin erosion. J Endod 2011;37:1437-1441.

14. Stojicic S, Shen Y, Qian W, Johnson B, Haasapalo M. Antibacterial and smear layer removal ability of a novel irrigant, QMix. Int Endod J 2012;45:363-371.

15. Wu MK, Wesselink PR. Efficacy of three techniques in cleaning the apical portion of curved root canals. Oral Surg Oral Med Oral Path 1995;79:492-49.

16. Çalt S, Serper A. Smear Removal by EGTA. J Endod 2000;26:459461.

17. Teixeira CS, Felippe MCS, Felippe WT. The effect of application time of EDTA and $\mathrm{NaOCl}$ on intracanal smear layer removal: an SEM analysis. Int Endod J 2005;38:285-290.

18. Kuah H-G, Lui J-N, Tseng PSK, et al. The effect of EDTA with and without ultrasonics on removal of the smear layer. J Endod 2009;35:393-396.

19. Mello I, Robazza CRC, Antoniazzi JH, et al. Influence of different volumes of EDTA for final rinse on smear layer removal. Oral Surg Oral Med Oral Pathol Oral Radiol Endod 2008;106:40-43.

20. Hasheminia SM, Birang R, Feizianfard M, Nasouri M. A comparative study of the removal of Smear Layer by two endodontic irrigants and Nd:YAG laser: A scanning Electron Microscopic Study. ISRN Dent 2012:1-7.

21. Zhang C, Kimura Y, Matsumoto K, Harashima T, Zhou H. Effects of pulsed Nd:YAG laser irradiation in root canal wall dentin with different laser initiators. J Endod 1998;24:352-335.

22. Barbakow F, Peters O, Havranek. Effects of Nd:YAG lasers on root canal walls: a light and scanning electron microscopic study. Quintessence Int 1999;30:837-845.

23. Kivanç BH, Ulusoy OIA, Görgül G. Effects of Er:YAG laser and Nd:YAG laser treatment on the root canal dentin of human teeth: a SEM study. Lasers Med Sci 2008;23:247-252.

24. Moura-Netto C, de Moura AAM, Davidowicz H, Aun CE, Antonio MPS. Morphologic changes and removal of debris on apical dentin surfaces after Nd:YAG laser and diode laser irradiation. Photomed Laser Surg 2008;26:263-266.

\section{Conflicts of Interest}

The authors declare that they have no conflict of interest. 